Article

\title{
How Population Age Distribution Affects Future Electricity Demand in Korea: Applying Population Polynomial Function
}

\author{
Ha-Hyun Jo ${ }^{1}$, Minwoo Jang ${ }^{2, * \mathbb{C}}$ and Jaehyeok Kim ${ }^{3}$ (1) \\ 1 Department of Economics, Yonsei University, 50 Yonsei-ro, Seodaemun-gu, Seoul 03722, Korea; \\ hahyunjo@hanmail.net \\ 2 Korea Power Exchange, 625 Bitgaram-ro, Naju City 58322, Korea \\ 3 Yonsei Economic Research Institute, 50 Yonsei-ro, Seodaemun-gu, Seoul 03722, Korea; safin84@gmail.com \\ * Correspondence: maretyno@kpx.or.kr
}

Received: 22 September 2020; Accepted: 9 October 2020; Published: 14 October 2020

check for updates

\begin{abstract}
Mounting evidence shows that economic and climate variables such as income, energy price, and temperature impact energy demand. We examined another variable, population age distribution, which has rarely been considered, that could affect energy demand. We employ population polynomials to account for the impact of population age distribution on residential electricity consumption in Korea. Using panel data from 1990 to 2016, we verify that populations aged 20 44, and those over 60, raise residential electricity consumption. We additionally evaluate the impact of population age distribution in forecasting future electricity consumption and conclude that age distribution effects dominate total population growth effects.
\end{abstract}

Keywords: electricity demand; population age distribution; population aging; population polynomials; electricity demand forecast

JEL Classification: Q43; J1; R11

\section{Introduction}

The UN has identified 15 major issues that humankind will face in the coming years; one of these is a growing population [1]. At issue is not only the total growth in population, but also the aging of the world's population. Due to an increase in life expectancy, caused by improved welfare, and a low fertility rate, the population of seniors will continue to grow. These issues will remain high on the international policy agenda as they affect various aspects of the economy. In the past, an aging population has been a problem only for developed economies; however, it has now become a problem for developing economies as well.

Korea has also been facing issues due to a problematic distribution of ages in its population. According to Statistics Korea, the Korean statistics authority, the fertility rate has been decreasing since the mid-1980s, and this trend accelerated in the 1990s due to many socio-economic reasons, such as an increase in child support expenses, a decline of the child mortality rate, and a trend of later marriage (The World Development Indicator (WDI) indicates that the fertility rate in Korea was 1.17 in 2016 , which is the lowest level in the world). In 2018, the proportion of the population aged 65 and over $(13.8 \%)$ exceeded that of the population aged under $14(13.1 \%)$ for the first time since the statistics were compiled. Aging societies are a prevailing phenomenon across the world, but the pace is especially rapid in Korea. As of 2018, Korea has become an aging society, and it is expected to become an aged society within 17 years (An aging society refers to a society where the proportion of the population aged over 65 exceeds $7 \%$, while in an aged society that proportion exceeds $14 \%$ ). This pace is extremely 
rapid relative to that of France, Germany, the USA, and Japan, which will reach this point in $154,77,94$, and 24 years, respectively.

A large volume of literature has examined the effect of population age distribution, including population aging, on various economic sectors. From a macroeconomic perspective these effects can be summarized in three important topics: a decline in the potential economic growth rate and size of the economy due to a lowering of the working age population, an impact on financial markets due to changing savings and investment preferences, and a change in consumption patterns.

Among these, identifying consistent patterns of change in the consumption of goods and services caused by population aging is not an easy task. In particular, many experts find it difficult to identify the effects of population age distribution on electricity because, in addition to economic factors, social and cultural practices, such as living patterns, and the propensity to conserve energy differ by age group [2-5]. Despite many difficulties, investigating the relationship between age distribution and electricity demand is very important for Korea in order to secure a stable energy supply and forecast demand. Economic and climate factors are allegedly the major variables affecting energy demand. However, these variables can only partly explain consumer behavior, and preferences based on demographic changes are now being considered as drivers of energy demand. Among the demographic factors, population age distribution could play an important role in electricity consumption in various ways. In general, older people are less active than younger ones; thus, they prefer to stay inside their homes. Additionally, they are more sensitive to changes in weather. As such, an increase in the older population can raise electricity consumption [6-15]. However, an increase in the older population may have the opposite effect on electricity consumption. Even though they spend more time inside their homes than younger people, their usage of electronic appliances might be less intensive because older people are not familiar with electronic gadgets and are conservative in consuming electricity [16-20].

These population-age-distribution effects on energy consumption are directly related to greenhouse gas (GHG) emissions [21]. In the coming regime, which is aimed at tackling climate change, not only developed economies but also developing economies have an obligation to reduce GHGs by their Nationally Determined Contributions (NDC). In many energy policy analyses, demographic factors are not generally considered in the models. A few articles include demographic factors in analyzing energy consumption, but they only consider how they indirectly affect energy consumption through economic channels $[9,17,22]$. Population aging may trigger consumption switching, which diminishes GHG reduction efforts [23]. Therefore, understanding the impact of population age distribution on electricity consumption is important for effective environmental and energy policies [16].

In this article, we examine the role of population age distribution, particularly population aging, on residential electricity demand using Korean regional panel data. Korea has one of the fastest growing elderly populations and is one of the heaviest energy users. Therefore, analyzing the relationship between population age distribution and residential electricity consumption is particularly important for Korea since the two issues have been remained high on policy agendas for a long time. Most of the previous literature has placed emphasis on traditional economic and climatic determinants, such as income, price, and temperature [24-29]. Only recently has attention been paid to the role of population age distribution on electricity demand. In addition, most of the previous literature uses aggregate-level data, including for demographic factors such as aging index and aggregate age-group proportion [8,10,18,20,30-32], or household-level survey data for very short periods $[7,9,11,12,15,16,19,33,34]$. It is clear that each type of data has pros and cons. Using aggregate-level data, we can analyze electricity consumption behavior in a national scope, which enables us to forecast future electricity consumption and set up a national energy plan. On the other hand, micro-household data allows us to incorporate more detailed information regarding residential electricity consumption by including many control variables, such as age of the head of household, gender, marital status, housing type, and so on. In this article, we employ a population polynomial function, following [35], to reflect the age profiles of the whole nation in an effort to combine the advantages of each data type. By employing the population polynomial function, we can 
account for the heterogeneity in age-specific consumption patterns, which can combine the advantages of aggregate and survey data. To our knowledge this is the first article to use a population polynomial function in an energy study.

In addition to estimation, we perform various robustness tests to make the estimation results more concrete. We also perform a conditional forecast of future residential electricity consumption up to the year 2030 by exploiting population projections given by Statistics Korea.

This paper is organized as follows. Section 2 reviews the previous literature. Section 3 illustrates the data and empirical model adopted in the analysis and presents the empirical results. In Section 4, we forecast future residential electricity consumption. Section 5 concludes the study.

\section{Literature Review}

Population age distribution variables have been only recently considered as additional factors affecting electricity demand. The following Table 1 summarizes the main results of previous studies. We classify them into two criteria, effect of population age distribution on energy demand and the data used.

Table 1. Literature survey on the effect of aging on energy demand.

\begin{tabular}{ccc}
$\begin{array}{c}\text { Effect of Population Age } \\
\text { Distribution on Energy Demand }\end{array}$ & Literatures & Data \\
\hline Aging increases energy demand & {$[6,7,9,11,12,15,36]$} & $\begin{array}{c}\text { Micro cross-section data } \\
\text { Macro panel data }\end{array}$ \\
\hline \multirow{2}{*}{ Aging decreases energy demand } & {$[16,10,13,31,32]$} & Micro cross-section data \\
& {$[17,18,20]$} & Macro \& regional panel data \\
\hline Aging effect is mixed & {$[34]$} & Micro cross-section data \\
& {$[30]$} & Macro panel data \\
\hline
\end{tabular}

Much literature investigates the role of age distribution on electricity demand, but little consensus has been reached since income trends, consumer preferences, and culture are different in every society. One strand of articles insists that elderly people consume more electricity $[6-13,15,31,32,36]$. These articles suggest three reasons for their conclusions. First, elderly people are physically more inactive than younger people and tend to stay home longer. Second, they tend to try to maintain a consistent internal temperature to keep their health. Third, they tend not to upgrade their inefficient electronic appliances, which can increase electricity consumption.

Ref. $[6,7,9,11,12,15,36]$ conduct cross-sectional analyses using micro-survey data, and they suggest that, in general, energy consumption increases with age. Ref. [6] analyzes the influence of population aging on energy expenditure using repeated cross-section data from Italy. They employ a pseudo-panel regression and find that aging causes an increase in energy expenditure. Ref. [7] finds that energy consumption reaches the highest point at a median age of over 40, and [15] find that older households consume more electricity based on urban Chinese survey data. Ref. [9] constructs the consumption-switching channel caused by population aging using the Household income and expenditure survey 2010. Following [37], they employ an input-output analysis and conduct a long-term energy consumption projection from 2010 to 2035. In spite of the aging population, it is projected that consumption-related energy use will have an upward trend since cooling and heating demands are dominant factors. Ref. [11] draws data from the US Residential Energy Consumption Survey (RECS) and suggest that mean per capita energy consumption is upward sloping with rising age. Ref. [12] effectively describes the possible channels of the effects of population aging on residential electricity consumption using a Japanese case. They suggest the number of households, income level, residential type, ownership of durable goods, energy conservation behavior, and lifestyle can be channels of residential electricity usage. They conclude that population aging raises electricity consumption, but, at the same time, they suggest that the effects of population aging might be different 
for other societies. Ref. [36] investigates the determinants affecting energy expenditure using Indian household survey data from 1993 1994. From their regression results, the coefficients for the age of the head of household dummy show upward values as the age increases, and it reaches its highest point at the age of $55 \sim 59$.

Ref. $[8,10,13,31,32]$ uses country or regional panel data for their analyses. Ref. [8,10] examines the Korean case. Ref. [8] uses Korean regional panel data for 2000 to 2016 and estimate the short- and long-run effect of population age structure on residential electricity demand. They find that an increase in the youth population and population aged 65 and over raise electricity demand. Ref. [10] constructs a Korean regional panel of 16 regions during 2001 2010 and conclude that the ratio of the population aged over 65 exerts a positive effect on residential electricity consumption. Ref. [13] conducts the analysis using national data from 14 founding EU members covering the period of 1960 2000 and concludes that a population aged over 65 has a positive effect on commercial energy consumption. Ref. [31] includes four key age groups: 20 34, 35 49, 50 69 and over 70. They focus on 17 developed countries spanning 1960 2005 and find that a population aged 65 79 raises residential electricity consumption. Ref. [32] applies a fully-modified OLS (FMOLS) to account for non-stationarity in time-series data using panel data from 22 OECD countries spanning 1960 2007. They decompose total population into the four key age groups mentioned above and find that the youngest and oldest cohorts exert positive effects on residential electricity consumption.

The other strand of articles insists that aging populations decrease the energy demand [16-20,33]. They attribute the results to a lower intensity of energy consumption. Even though older people stay inside longer, they do not use energy-intensive appliances much. Additionally, an aging population has negative effects on supply side and disposable income. Therefore, reduced disposable income leads to lowering energy consumption.

Ref. [16] investigates the Dutch case. They study the effects of household characteristics on electricity demand using a large number of household survey data. They run a cross-sectional regression model and find that aging causes a decrease in electricity consumption. However, on the other hand, households with younger people lead to an increase in electricity consumption. This is because younger people watch more TV, use personal computers, and are heavy users of gaming devices, which is described as the 'Nintendo-effect'. Ref. [17] employs a calibrated overlapping generations (OLG) equilibrium model. Adopting Italy as a case study, they find that a pronounced aging population causes a reduction in energy consumption through the supply channel. Two articles conclude that population aging has a negative effect on electricity consumption in Korea. Ref. [18] estimates a long-run autoregressive distributed lags (ARDL) model and short-run error-correction model (ECM) using Korean aggregate time series data from 1966 to 2011. They conclude that the aging index exerts a negative effect on per capita residential electricity consumption both in the long- and short-run. Ref. [19] finds that the presence of elders aged over 65 in a household decreases electricity consumption based on a 2008 household survey data. Ref. [20] employs a panel data analysis, on the Japanese prefecture level, of residential electricity. The demographic variables they consider are the proportion of the people aged 65 or above and total fertility rate. In their article, population aging has negative effects on electricity demand, but the total fertility rate has no effects. Ref. [33] investigates the Chinese case. Using residential energy consumption (REC) data from household surveys in 2005 and 2010, they find that level of per capita REC of people aged over 60 is lower than people aged 0 59 in both years.

In addition, two strands of literature, Ref. [30,34], show mixed effects of population aging on residential electricity consumption. Ref. [30] employs a dynamic panel regression using a country panel, composed of 53 countries, from 1976 2009. They show evidence of increasing electricity consumption with rising population aging, but after the population aging reaches a certain level it decreases electricity consumption, which is an inverted U-shaped curve. Ref. [34] concludes that population aging has a negative effect with low-income groups, a positive effect with middle-income groups, and no effect with high-income groups based on the Korean Household income and expenditure survey 2013. 
In previous literature, most of the research has been done using micro-level survey data, but only a few articles use macro-level aggregate data. We suppose the popularity of micro-data is that it provides explicit age information for individuals, whereas macro-data cannot practically account for the whole population of each age group.

However, in order to overcome the aforementioned obstacles using time-series or aggregate variables, ref. [35] developed population polynomial functions to account for age-based population heterogeneity. They investigated how age distribution affects consumption, housing investment, money demand, and real income based on the US economy by applying the Almon method. Following [35], four articles apply the same population polynomials in their research and examine the effect of age distribution on macroeconomic variables such as domestic savings, investment, and current account [38]; GDP and stock and bond markets [39]; and inflation rate [40]. They suggest the following two advantages of using population polynomial functions. First, it has the advantage of capturing the information contained in an entire age distribution [38]. Second, it allows intuitive interpretations since the model is parsimonious and continuous across age groups [39].

\section{Empirical Analysis}

\subsection{Methodology}

In this article, we take population polynomials function in our empirical model to account for detailed age profile. As we mentioned earlier in previous section, most of the existing literature reflect population age structure as certain cohorts, such as, population aged 65 and above, working age population, youth population, and so on. They can be a good proxy of population age distribution of whole economy, though, are not enough to account for high degree of heterogeneity. For example, previous literature hardly includes the effect of population aged $0 \sim 4,5 \sim 9, \ldots, 75 \sim 79$ and over 80 on energy demand since they only reflect representative age groups. Therefore, we try to include as much information of population age distribution as possible. To our knowledge, this is the first article to include population polynomials in study of energy demand.

The basic regression equation to estimate the age distribution effect on electricity is as follows.

$$
E_{h, t}=\delta+X_{h, t} \beta+\alpha_{1} D 1_{h, t}+\alpha_{2} D 2_{h, t}+\cdots+\alpha_{J} D J_{h, t}+U_{h, t}
$$

$E_{h, t}$ is the dependent variable, total residential electricity consumption for individual $h$ in period $t$. Let $D 1_{h, t}$ be 1 if individual $h$ is in age group 1 in period $t$, and 0 otherwise. $X_{h, t}$ denotes explanatory variables. In most cases, it is not easy to find economic data for each age group at the macroeconomic level. At the micro level, such as household surveys, we can obtain data for each age group, but in most cases this data does not contain time series information. Furthermore, micro data does not represent a whole country. For these reasons, using macro-panel data is favorable, but the limited information for each age group makes it harder to estimate Equation (1).

Following [35], we restrict the coefficient, $\alpha_{j}$, to satisfy a $k$ th-order polynomial, allowing us to incorporate age group information. The derivation of the estimable regression equation is as follows.

First, aggregating Equation (1) for every $h$ leads to Equation (2).

$$
E_{t}=\delta N_{t}+X_{t} \beta+\alpha_{1} N_{1 t}+\alpha_{2} N_{2 t}+\cdots+\alpha_{J} N_{J T}+U_{t}
$$

Dividing both sides by the total population $N_{t}$ gives us the following Equation (3)

$$
e_{t}=\delta+x_{t} \beta+\alpha_{1} p_{1 t}+\alpha_{2} p_{2 t}+\cdots+\alpha_{J} p_{J t}+u_{t}
$$

where $e_{t}$ and $x_{t}$ are per capita residential electricity consumption and explanatory variables in per capita terms, respectively. $p_{j t}$ is the share of population in age group $j$ to the total population. Equation 
(3) is estimable since we have Korean population census data for each age group. The coefficients $\alpha_{1}$, $\ldots, \alpha_{J}$ are estimated under the following restrictions.

Restriction 1. $\sum_{j=1}^{J} \alpha_{j}=0$

Restriction 2. $\alpha_{j}$ is expressed in the polynomial of order k (e.g., $\alpha_{j}=\gamma_{0}+\gamma_{1} j+\gamma_{2} j^{2}+\cdots+\gamma_{k} j^{k}$ )

Based on Equation (3), and with the two restrictions, our finalized regression model takes the following form (For the detailed derivation of Equation (4), see $[38,39]$ ).

$$
e_{i t}=\delta+x_{i t} \beta+\gamma_{1} z_{i t}+\gamma_{2} z_{i t}^{2}+\cdots+\gamma_{k} z_{i t}^{k}+\mu_{i}+u_{i t}
$$

Restriction 1 is included in order to avoid a dummy trap since the sum of $p_{j t}$ is 1 , and without this restriction $\gamma_{0}$ cannot be calculated. Additionally, Restriction 2 is needed to reduce the coefficients to be estimated since Equation (3) reflects many age-group effects and allows us to incorporate all the demographic profile information. Given the estimates of $\gamma_{1}$ to $\gamma_{k}$, the coefficient $\alpha_{j}$ can be computed by Almon's distributed lag technique (Fair and Dominguez, 1991). In the above Equation (4), we apply a maximum fifth-order polynomial based on previous literature. Ref. [35], the first article employing the population polynomial function, set a second-order polynomial to analyze the life-cycle effect on the macroeconomy. However, ref. [39] employs a maximum fourth-order polynomial, whereas [40] take a maximum sixth-order polynomial. We decided the most appropriate order of polynomial by conducting a Wald test for the nested model.

\subsection{Data and Descriptive Statistics}

In this study we use regional-level panel data for 15 regions in Korea during 1990 to 2016. In analyzing with time series data there is a strong correlation between age distribution and income because, in general, population aging is accelerated with growing income. Using micro data can be an alternative solution to the problem, but it cannot include the time-varying effect unless it is collected over a long period, and micro data does not represent a nation-wide sample. To overcome the above-mentioned problems, we use the regional-level panel data.

Since 1998, Korea has been divided into 16 regions (Seoul, Busan, Daegu, Incheon, Gwangju, Daejon, Ulsan, Gyeonggi, Gangwon, Chungbuk, Chungnam, Jeonbuk, Jeonnam, Gyeongbuk, Gyeongnam, and Jeju). Before 1998, Ulsan was a part of Gyeongnam, hence electricity consumption data for Ulsan from 1990 1997 does not exist, and we only have the data for Gyeongnam. To construct balanced panel data and to secure a time series from 1990, we consolidate the data for Ulsan and Gyeongnam into one.

As we previously mentioned the dependent variable, $e_{i t}$ is per capita residential electricity consumption in MWh. We extract total electricity consumption data from the Electric Power Statistics Information System (EPSIS) and total population from the Korea Statistics Information Service (KOSIS). We include the explanatory variables, income, energy price, and climate. $y_{i t}$ is per-capita gross regional domestic production (GRDP) in KRW1000 extracted from KOSIS. To create a consolidated GRDP for Gyeongnam, we add up the GRDP of Ulsan and Gyeongnam and divide by total population. For the energy price variables, we include average residential electricity price in real terms, $p e_{i t}$, deflated by the consumer price index (CPI), which is taken from EPSIS. We consolidate the CPI of Ulsan and Gyeongnam by applying a weighted average of GRDP. Heating Degree Days, $H D D_{i t}$, and Cooling Degree Days, $C D D_{i t}$, are taken to capture the temperature effect, and they are extracted from the Korea Meteorological Administration (KMA). Finally, age distribution data in five-year intervals, $0 \sim 4,5 \sim 9$, $\ldots, 75 \sim 79$, and over 80 (seventeen age groups in all) are taken from KOSIS. Table 2 displays descriptive statistics of the main variables and Figure 1 depicts the trends of the main variables. 
Table 2. Descriptive statistics.

\begin{tabular}{cccccc}
\hline Variable & $\boldsymbol{e}_{\boldsymbol{i t}}$ & $\boldsymbol{y}_{\boldsymbol{i t}}$ & $\boldsymbol{p \boldsymbol { e } _ { \boldsymbol { i t } }}$ & $\boldsymbol{H D D}_{\boldsymbol{i t}}$ & $\boldsymbol{C D D}_{\boldsymbol{i t}}$ \\
\hline Mean & 0.89 & 16,800 & 1.46 & 2417 & 756 \\
Median & 0.91 & 15,244 & 1.46 & 2474 & 754 \\
Max & 1.47 & 49,865 & 1.77 & 3357 & 1130 \\
Min & 0.31 & 3198 & 1.20 & 1323 & 416 \\
SD & 0.29 & 9378 & 0.15 & 429 & 123 \\
SK & -0.17 & 0.89 & 0.01 & -0.36 & 0.04 \\
KT & 1.72 & 3.47 & 1.78 & 2.45 & 2.90 \\
\hline
\end{tabular}

Electricity consumption per capita (MWh)

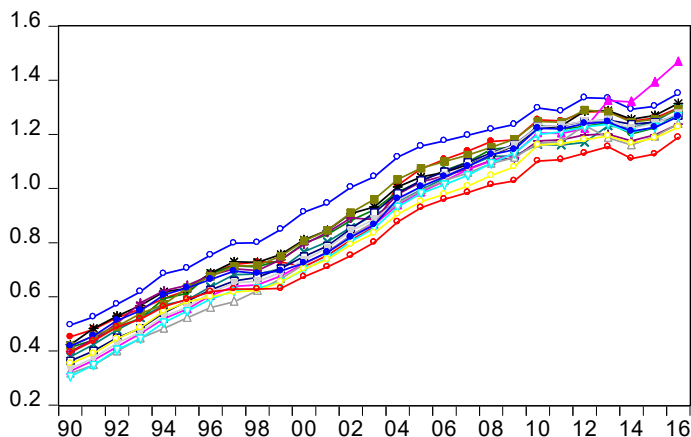

\begin{tabular}{|c|c|c|}
\hline $\begin{array}{ll}\ldots & \text { Seoul } \\
\ldots & \text { Incheon } \\
\square- & \text { Gyeonggi } \\
\square- & \text { Chungnam } \\
& \text { Gyeongbuk }\end{array}$ & $\begin{array}{ll}\longrightarrow & \text { Busan } \\
\ldots & \text { Gwangju } \\
\longrightarrow & \text { Gangwon } \\
\longrightarrow & \text { Jeonbuk } \\
\longrightarrow & \text { Gyeongnam }\end{array}$ & $\begin{array}{ll}\_ & \text {Daegu } \\
\square & \text { Daejeon } \\
\longrightarrow & \text { Chungbuk } \\
\square & \text { Jeonnam } \\
\square & \text { Jeju }\end{array}$ \\
\hline
\end{tabular}

Share of population aged under 15
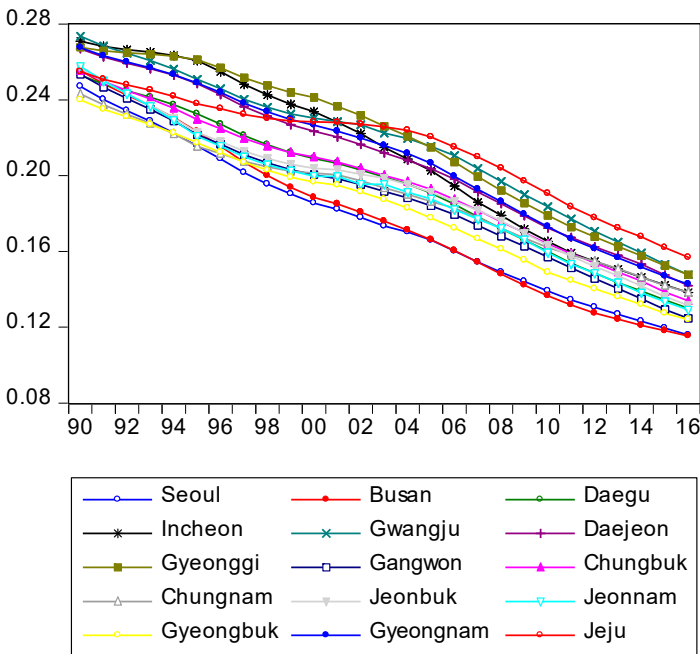

GRDP per capita (1,000won)

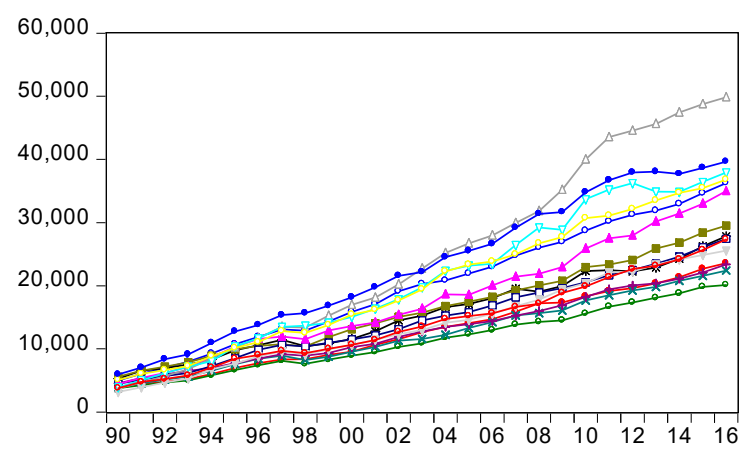

\begin{tabular}{|lll|}
\hline Seoul & $\longrightarrow$ Busan & Daegu \\
$\longrightarrow$ Incheon & G Gwangju & Daejeon \\
$\longrightarrow$ Gyeonggi & $\longrightarrow$ Gangwon & Chungbuk \\
$\longrightarrow$ Chungnam & Jeonbuk & Jeonnam \\
Gyeongbuk & $\longrightarrow$ Gyeongnam & Jeju
\end{tabular}

Share of population aged 65 and over

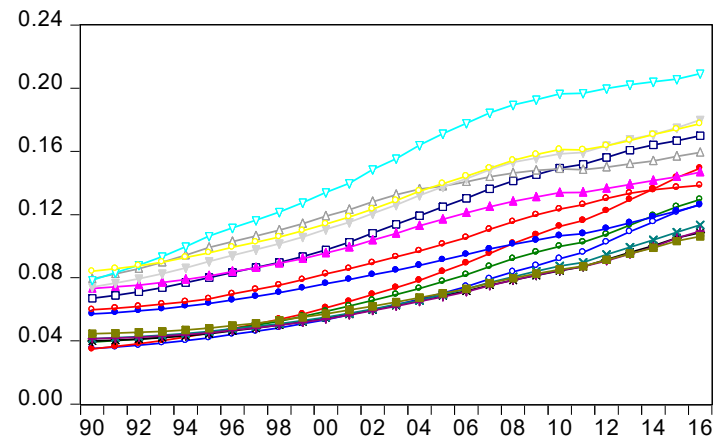

\begin{tabular}{|c|c|c|}
\hline $\begin{aligned} & \text { Seoul } \\
& \ldots \text { Incheon } \\
& \ldots \text { Gyeonggi } \\
& \ldots \text { Chungnam } \\
& \text { Gyeongbu }\end{aligned}$ & 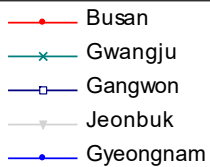 & $\begin{array}{l}\text { Daeg } \\
\square \text { Daeje } \\
\square \text { Chung } \\
\square \text { Jeonn } \\
\square \text { Jeju }\end{array}$ \\
\hline
\end{tabular}

Figure 1. Time series plots of primary variables.

\subsection{Estimation Results}

Table 3 displays the estimation results of Equation (4) in logarithmic form. We estimate equation (4) by a with-in estimator accompanied by a Cochrane-Orcutt transformation of the AR(1) error term to account for serial correlation. Standard error is clustered by cross-section. From Models 1 to 3 , we apply different forms of energy price variables to reflect the price effect. Generally, it is not an easy task to reflect the price effect in empirical time-series analysis and macro-panel analysis at the aggregate level since we take average electricity price of Korea in our model. Furthermore, Korean 
consumers respond to high electricity price in summer and winter because of inverted-block pricing for retail residential electricity usage, and such pricing is decided by the electricity authority (In contrast, Korea uses a competitive wholesale electricity market and what is called a cost-based pool (CBP) market). Besides summer and winter, with less consumption, electricity price does not rise enough to induce consumers to reduce electricity consumption. Therefore, we include the interaction term of electricity price and climate, HDD and CDD, in order for estimated coefficient of price variable to be negative which is consistent with economic theory. Where age distribution is concerned, we take fourth-order population polynomials due to the results of the Wald test.

Table 3. Estimation results of the baseline models.

\begin{tabular}{|c|c|c|c|}
\hline & Model (1) & Model (2) & Model (3) \\
\hline$y_{i t}$ & $0.18^{* * *}$ & $0.18^{* * *}$ & $0.19^{* * *}$ \\
\hline$p e_{i t}$ & & 0.04 & $-0.22 * * *$ \\
\hline$H D D_{i t} \times 10,000$ & $0.27^{* * *}$ & $0.28^{* * *}$ & \\
\hline$C D D_{i t} \times 10,000$ & $0.78^{* * *}$ & $0.77^{* * *}$ & \\
\hline$p e_{i t} \times H D D_{i t} \times 10,000$ & & & $0.71^{* * *}$ \\
\hline$p e_{i t} \times C D D_{i t} \times 10,000$ & & & $1.67^{* * *}$ \\
\hline$z^{1}$ & $7.23^{* * *}$ & $7.12^{* * *}$ & $7.74^{* * *}$ \\
\hline$z^{2} \times 10$ & $-12.94^{* * *}$ & $-12.65^{* * *}$ & $-14.25^{* * *}$ \\
\hline$z^{3} \times 100$ & $9.10^{* * *}$ & $8.84^{* * *}$ & $10.23^{* * *}$ \\
\hline$z^{4} \times 1000$ & $-2.20 * * *$ & $-2.13^{* * *}$ & $-2.51 * * *$ \\
\hline $\mathrm{AR}(1)$ & & $0.90^{* * *}$ & \\
\hline Adj-R ${ }^{2}$ & & 0.99 & \\
\hline obs. & & 390 & \\
\hline$\gamma_{1}=\gamma_{2}=\gamma_{3}=\gamma_{4}=0$ & $70.16^{* * *}$ & $69.17^{* * *}$ & $70.80 * * *$ \\
\hline $\mathrm{k}=5 \rightarrow \mathrm{k}=4$ & 2.03 & 1.80 & 2.46 \\
\hline $\mathrm{k}=4 \rightarrow \mathrm{k}=3$ & $5.57 * *$ & $5.11 * *$ & $7.28^{* * *}$ \\
\hline
\end{tabular}

The last two rows report the Wald statistics for comparisons between the nested models, opposing a fifth-order and fourth-order polynomial and a fourth-order and third-order polynomial. $z^{1}, z^{2}, z^{3}$, and $z^{4}$ variables represent the age distribution effect, and they are statistically significant. We additionally find that age distribution effects are jointly statistically significant through the Wald statistics $\left(\mathrm{H}_{0}\right.$ : $\left.\gamma_{1}=\gamma_{2}=\gamma_{3}=\gamma_{4}=0\right)$. Figure 2 shows the impact of age distribution on residential electricity demand using the estimated coefficients from Models 1 to 3.

We find an M-shaped curve for the age distribution effect, which is different from the U-shaped curve of the life-cycle hypothesis. Therefore, we try to interpret the results from a behavioral perspective. First of all, the figure shows us that the population aged under twenty has a negative effect on electricity consumption. This could be attributed to the effect of economies of scale from living together with their parents, and parents might educate their children to save energy [5]. However, the negative effect of this youth population continuously decreases in later years, and finally it becomes a positive effect since people in their late teens watch more TV, use computers more, and operate gaming and electronic devices [16]. Next, we turn our focus to the working age group. The figure indicates that populations aged 20 45 have the most positive effect on electricity consumption, which is in line with previous literature $[13,31,36]$. On the other hand, among the working age group, populations aged 45 59 slightly reduces electricity consumption. This can be interpreted as a precautionary savings motive because the population aged 45 59 might be expecting retirement or have already retired. In order to prepare for life after retirement, they try to reduce aggregate consumption and raise savings. 


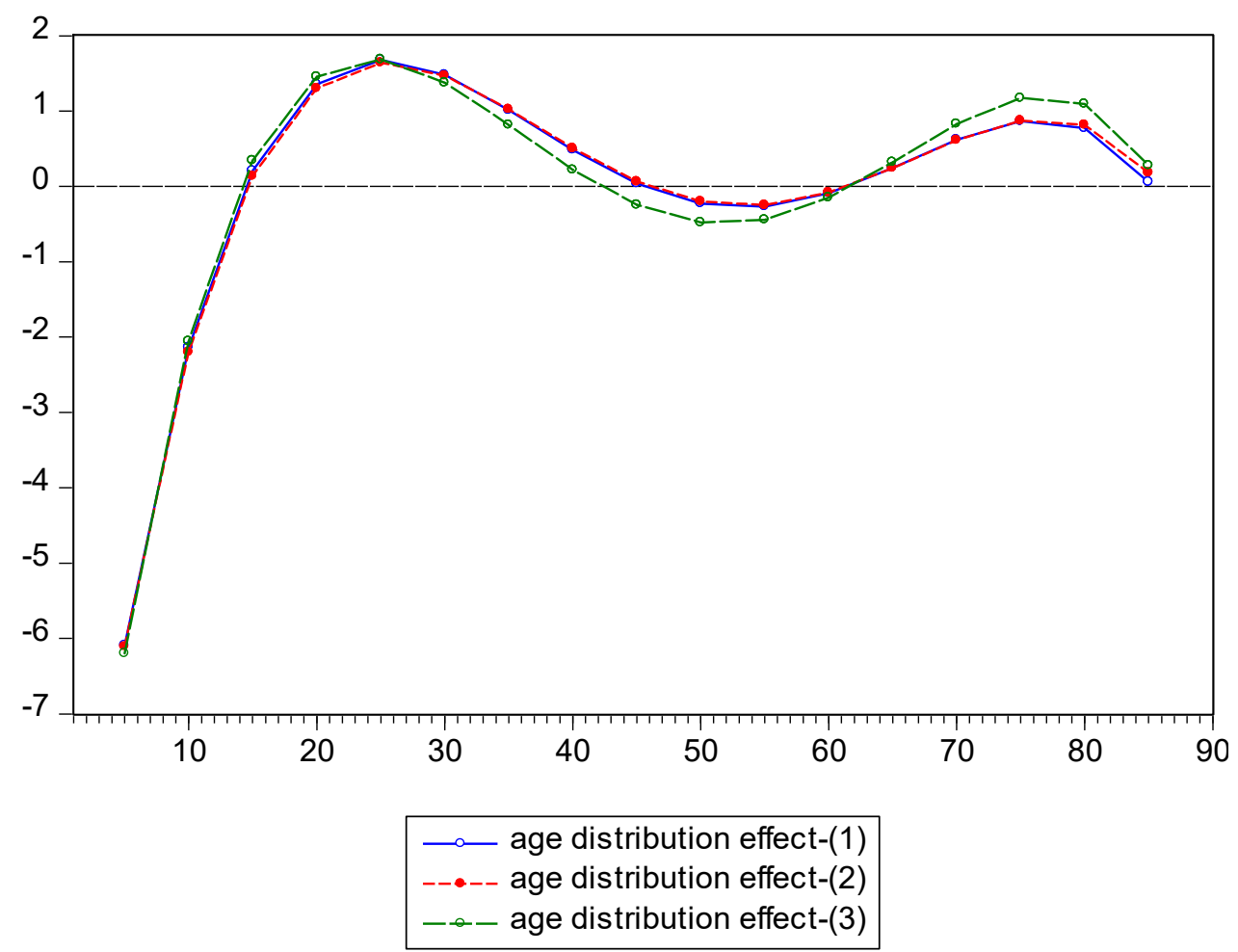

Figure 2. Age distribution effect on residential electricity demand.

The figure shows that populations aged over 60 raise electricity consumption, and we can explain this with various reasons. First of all, the tendency to be in single- or two-person households in old age gives us important implications. In the past, the traditional social norm in Korea was that younger households supported their parents by living together. However, this social norm has dramatically changed, with both younger and older populations preferring to have independent households. Generally, small-sized households are not favorable for conserving energy since they must be equipped with most appliances, such as washing machines, TVs, air-conditioners, and refrigerators, regardless of the number of members in the household, which means diseconomies of scale are in effect [15,41,42].

Second, many previous studies point out that older people tend to stay home longer due to their inactive lifestyles, which could increase residential electricity consumption. It is estimated that people aged over 65 spend more than $85 \%$ of their time at home, and this number rises to $90 \%$ for those aged over 85 [43]. Additionally, older people are more sensitive to weather; thus, they spend more electricity on heating and cooling to maintain their health.

Third, home ownership affects residential electricity consumption. Older households prefer to own their houses, and Korean statistics actually support this view. Owning a house reduces housing rental costs, and this cost savings could lead to rising electricity expenditure [7]. Fourth, gender can be an important factor. Many previous studies find empirical evidence that females use more electricity than males because they desire convenience and comfort $[7,16]$. The ratio of females is higher in populations over 60 due to the longer life expectancy of women, thus increasing female households could lead to rising electricity consumption.

The young generation, aged under 20, and older generation, aged 55 to 65 , have a negative effect on residential electricity demand, whereas those in the prime age group, aged 25 to 55 , have a positive effect. One of the possible explanations for the behavior of people aged 55 to 65 is a precautionary saving for the future. Ref. [44] find increasing precautionary savings due to the uncertainties of expected earnings in old age, life span, and liquidity constraints. We can interpret that as people aged 55 to 65 that expect to retire soon, or have already retired, reduce their residential electricity consumption. 


\subsection{Robustness Tests}

We undertook sensitivity tests to ensure that the solid relationship between population age structure and residential electricity consumption comes from consumer behavioral patterns. First, we divide our whole sample into three sub-samples, depending on income level: high-, middle-, and low-incomes. Second, we restrict our attention to two sub-periods, those before 2000 and those after 2000. None of these tests change the behavioral effects on electricity consumption.

\subsubsection{Different Income Sub-Samples}

In this section, we examine the heterogeneous age distribution effect of different incomes on residential electricity consumption. Ref. [34] suggest evidence that population aging can have a different effect on residential electricity consumption depending on income distribution by estimating the endogenous threshold income level. In this study, we divide the total sample into high-, middle-, and low-income groups by 75th percentile, 50th percentile, and 25th percentile, respectively, and run the following panel regression model.

$$
\begin{gathered}
e_{i t}=\delta+x_{i t} \beta+D_{L} \times\left(\alpha_{1 L} p_{1, i t}+\cdots+\alpha_{J L} p_{J, i t}\right)+D_{M} \times\left(\alpha_{1 M} p_{1, i t}+\cdots+\alpha_{J M} p_{J, i t}\right) \\
+D_{H} \times\left(\alpha_{1 H} p_{1, i t}+\cdots+\alpha_{J H} p_{J, i t}\right)+\mu_{i}+u_{i t}
\end{gathered}
$$

In Equation (5), $D_{L}, D_{M}$, and $D_{H}$ indicate the dummy variable for the low-, middle-, and high-income groups, taking the value of 1 if the sample falls under the specific categories, and 0 otherwise. The estimation results of Equation (5) are shown in Table 4. The estimation results show us that the optimal degree of population polynomial is different for each income group. The Wald statistics indicate that the fifth-order is optimal for the low-income group, whereas the fourth-order is optimal for the middle- and high-income groups. These results are different from the previously estimated baseline models which are fourth-order polynomials. Figure 3 displays the age-distribution effect on residential electricity consumption for the different income groups.

From Figure 3, we can infer that the pattern of all the income groups is qualitatively the same as the previous baseline model results. However, we can see slightly different results between the income groups. The population aged 20 44 in the middle- and high-income groups consume more electricity than the low-income group since they have more electronic appliances due to higher disposable incomes. For the population aged 45 59, the middle- and high-income groups consume less electricity than the low-income group, whereas they consume more when they are aged over 60.

\begin{tabular}{|c|c|c|c|}
\hline & Low-Income & Middle-Income & High-Income \\
\hline$y_{i t}$ & & $0.20^{* * *}$ & \\
\hline$p e_{i t}$ & & $-0.23^{* * *}$ & \\
\hline$p e_{i t} \times H D D_{i t} \times 10,000$ & & $0.74^{* * *}$ & \\
\hline$p e_{i t} \times C D D_{i t} \times 10,000$ & & $1.68^{* * *}$ & \\
\hline $\mathrm{z}^{1}$ & $11.98^{* * *}$ & $8.66^{* * *}$ & $8.89^{* * *}$ \\
\hline$z^{2} \times 10$ & $-28.87^{* * *}$ & $-16.12 * * *$ & $-17.03^{* * *}$ \\
\hline$z^{3} \times 100$ & $30.59 * * *$ & $11.61^{* * *}$ & $12.66^{* * *}$ \\
\hline$z^{4} \times 1000$ & $-14.91^{* * *}$ & $-2.84^{* * *}$ & $-3.20 * * *$ \\
\hline$z^{5} \times 10,000$ & $2.75^{* *}$ & & \\
\hline $\mathrm{AR}(1)$ & & $0.90^{* * *}$ & \\
\hline Adj-R ${ }^{2}$ & & 0.99 & \\
\hline obs. & & 390 & \\
\hline$\gamma_{1}=\gamma_{2}=\gamma_{3}=\gamma_{4}=0$ & $65.29 * * *$ & $82.54^{* * *}$ & $51.13^{* * *}$ \\
\hline $\mathrm{k}=5 \rightarrow \mathrm{k}=4$ & $7.51 * * *$ & 0.78 & 1.25 \\
\hline $\mathrm{k}=4 \rightarrow \mathrm{k}=3$ & & $11.41^{* * *}$ & $12.88^{* * *}$ \\
\hline
\end{tabular}

Table 4. Estimation results for different income groups.

*** $1 \%$ significance, ${ }^{* *} 5 \%$ significance. 


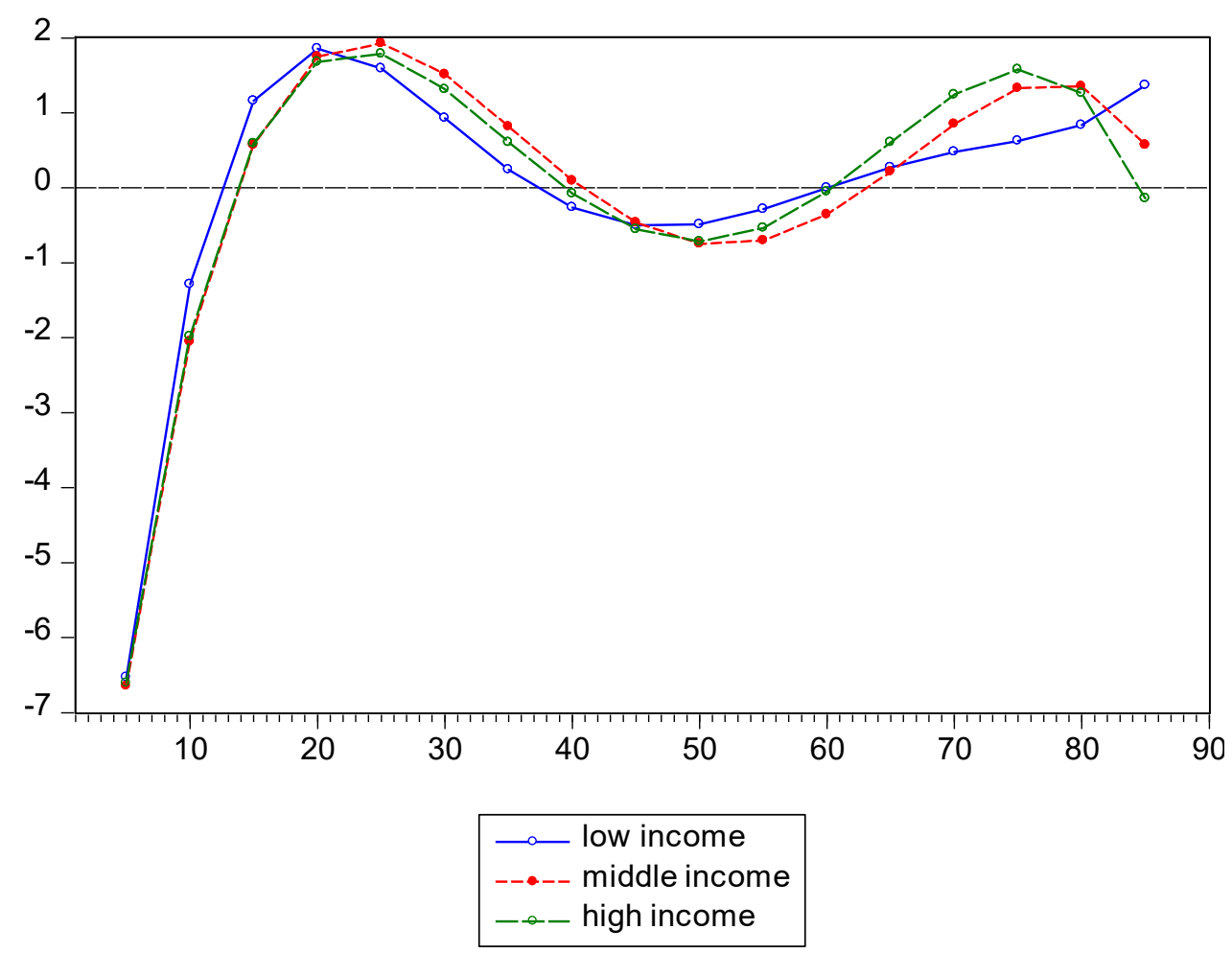

Figure 3. Age distribution effect on residential electricity demand for the different income groups.

A possible explanation for this is that the low-income group aged under sixty prefer to stay at home longer due to income constraints; thus, they consume relatively more electricity than middle- and high-income groups in their age bracket. Additionally, in terms of those aged over sixty, the low-income group cannot increase their electricity use by a large amount due to their relatively small disposable incomes, compared with those in the middle- and high-income groups.

\subsubsection{Different Time Periods}

We need to consider whether the baseline model results are specific to a particular period. This is especially important because Korea has experienced rapid economic dynamics, including rapid economic growth and the Financial Crisis, and this may have an effect on consumer behavior $([6,37,45]$ suggest that energy consumption behavior at different eras for the same cohort could show heterogeneous results because generations face different social and cultural norms). Thus, in this section we examine the relationship between population age distribution and residential electricity consumption in different sub-periods with the following regression model.

$$
\begin{gathered}
e_{i t}=\delta+x_{i t} \beta+D_{B} \times\left(\alpha_{1 B} p_{1, i t}+\cdots+\alpha_{J B} p_{J, i t}\right) \\
+D_{A} \times\left(\alpha_{1 A} p_{1, i t}+\cdots+\alpha_{J A} p_{J, i t}\right)+\mu_{i}+u_{i t}
\end{gathered}
$$

In Equation (6), $D_{B}$ and $D_{A}$ are dummy variables taking the value of 1 for the period before the year 2000 and after the year 2000, respectively. The reasons that we set the year 2000 as a reference year are as follows. First, since the time series we have is from 1990 to 2016, the year 2000 is an adequate reference date for acquiring enough observations for each sub-sample. Second, Korea experienced Energy Market Liberalization in 1997 and the Asian Financial Crisis around 1997 1998, which caused economic structural changes and possibly exerted an effect on consumption behavior, and we reasonably consider that the economy has stabilized since 2000.

Table 5 shows the estimation results of Equation (6), and Figure 4 displays the results from different time periods. The optimal degree for the population polynomial is found to be four, which is 
the same as the previous estimation. This means our regression model is robust regardless of time series. The results for the age-distribution effect on residential electricity consumption for different time periods are also qualitatively the same.

However, we can see smoother variation in the red-dashed graph, which is the effect post 2000. The population in their 20s and 30s during the post-2000 era consumed less than in the pre-2000 era. On the other hand, the population in their 40s and 50s during the post-2000 era consumed more than in the pre-2000 era. A possible explanation is that after 2000, the wide distribution of many electronic appliances, such as PCs, laptops, and smart devices caused various age groups to more easily consume electricity.

Table 5. Estimation results for different periods.

\begin{tabular}{|c|c|c|}
\hline & 1990-1999 & 2000-2016 \\
\hline$y_{i t}$ & & \\
\hline$p e_{i t}$ & & \\
\hline$p e_{i t} \times H D D_{i t} \times 10,000$ & & \\
\hline$p e_{i t} \times C D D_{i t} \times 10,000$ & & \\
\hline$z^{1}$ & $8.07^{* * *}$ & $7.45^{* * *}$ \\
\hline$z^{2} \times 10$ & $-14.77^{* * *}$ & $-13.62^{* * *}$ \\
\hline$z^{3} \times 100$ & $10.43^{* * *}$ & $9.71^{* * *}$ \\
\hline$z^{4} \times 1000$ & $-2.49^{* * *}$ & $-2.36^{* * *}$ \\
\hline $\operatorname{AR}(1)$ & & \\
\hline Adj- $R^{2}$ & & \\
\hline obs. & & \\
\hline$\gamma_{1}=\gamma_{2}=\gamma_{3}=\gamma_{4}=0$ & $50.84^{* * *}$ & $51.13^{* * *}$ \\
\hline $\mathrm{k}=5 \rightarrow \mathrm{k}=4$ & 1.55 & 1.25 \\
\hline $\mathrm{k}=4 \rightarrow \mathrm{k}=3$ & $8.11^{* * *}$ & $12.88^{* * *}$ \\
\hline
\end{tabular}

*** $1 \%$ significance.

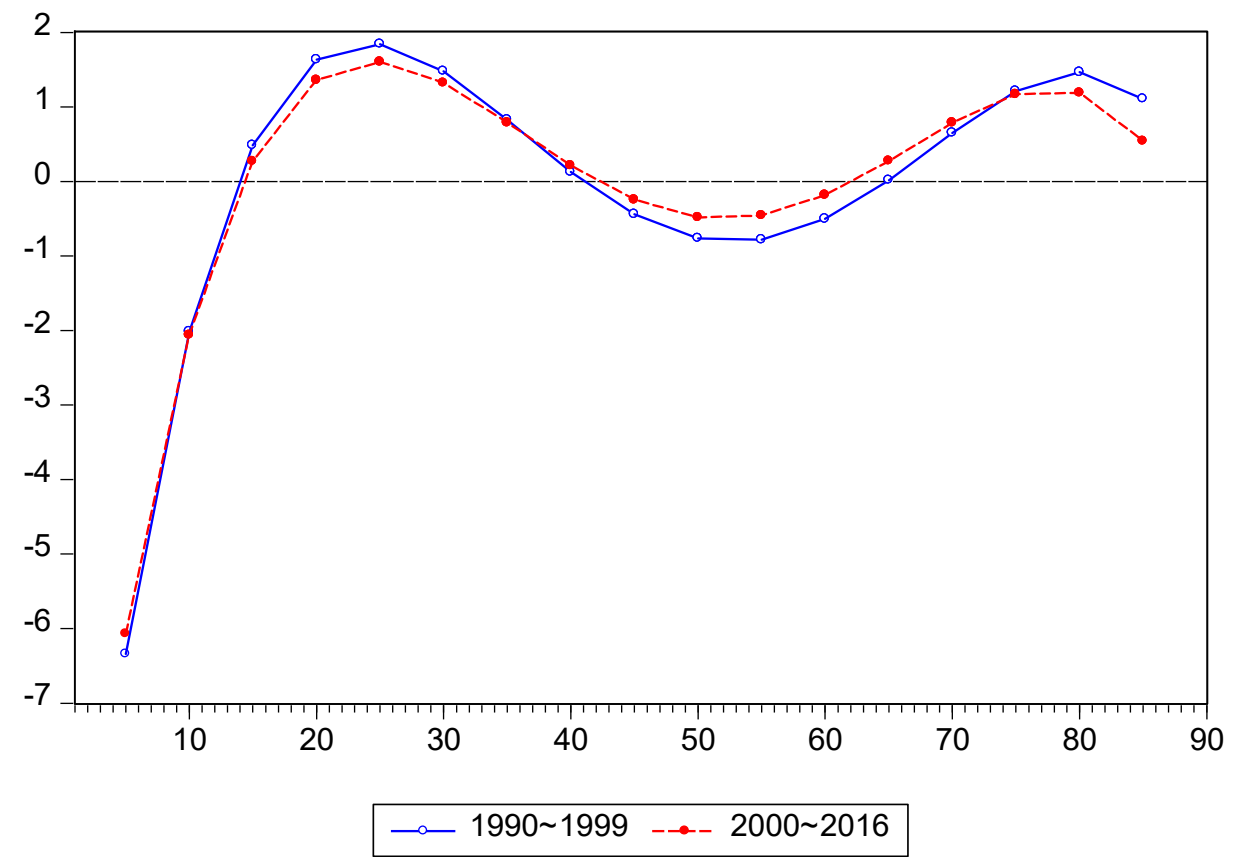

Figure 4. Age distribution effect on residential electricity demand in the different periods. 


\section{Long-Term Forecast of Future Residential Electricity Consumption}

In this section, we perform long-term conditional forecasting for future residential electricity consumption based on Model 3 in the baseline estimation. Our target horizon ranges from 2019 to 2031, which is the same end period as 'The 8th Basic Plan for Long-term Electricity Supply and Demand' in Korea [46]. In the baseline regression model, residential electricity consumption is explained by contemporaneous income per capita, electricity price, climate condition, and population age distribution. Therefore, we need future values of explanatory variables for conditional forecasting (If a dependent variable is explained by lagged dependent and independent variables, we do not need future values of them, and we call this methods "unconditional forecasting"). For the future macroeconomic conditions, GDP and CPI, we adopt the same forecasts used in 'The 8th Basic Plan for Long-term Electricity Supply and Demand' for consistency. For the future electricity price, we employ data provided by the Korea Power Exchange (KPX). Basically, it is projected in proportion to the total cost of the Korea Electric Power Corporation (KEPCO), the state-owned energy company, where total cost includes capacity payment for supply capacity and energy payment for power generation under the power mix plan. We take HDD and CDD as the climate conditions, and their future values are projected under the RCP6.0 (Representative Concentration Pathway) scenario provided by KMA.

The foremost determinants in this article, the estimated future population, is taken from KOSIS. It is estimated in three scenario cases: low, middle, and high, based on the variability of total fertility, life expectancy, and international net mobility in ascending order. Thus, the low scenario is the most conservative, and the high is the least conservative. Table 6 shows the average change rate in estimated future population for 2016 2031.

Table 6. Average change rate in the estimated future population.

\begin{tabular}{cccccc}
\hline \multirow{2}{*}{$\begin{array}{c}\text { Future } \\
\text { Scenario }\end{array}$} & \multirow{2}{*}{$\begin{array}{c}\text { Change in Total } \\
\text { Population (\%) }\end{array}$} & \multicolumn{3}{c}{ Change in Age Distribution (\%) } \\
\cline { 3 - 5 } & -0.02 & $\mathbf{0 ~ 1 9}$ & $\mathbf{2 0 ~ 4 4}$ & $\mathbf{4 5 ~ 5 9}$ & $\mathbf{6 0 \sim}$ \\
\hline Low & 0.22 & -1.98 & -1.62 & -0.55 & 3.95 \\
Mid & 0.45 & -0.93 & -1.64 & -0.72 & 3.84 \\
High & & -1.67 & -0.89 & 3.72 \\
\hline
\end{tabular}

Since our regression model is based on regional per capita electricity consumption, to see the nation-wide effect of demographics we first multiply the regional population by the per capita electricity consumption and then combine the 15 regional values into an aggregate national value.

Figure 5 displays the results of the future forecasts of residential electricity consumption. In the figure, we draw a black-stared line as a forecast without an age-distribution effect for a comparison between the three scenarios.

We can verify that the solid-blue line (low scenario) depicts the highest value and green-dotted line (high scenario) depicts the lowest value. The results are mainly attributed to the population-age-distribution effect. Although total population growth is the highest in the high scenario and the lowest in the low scenario, the population-aging effect is the highest in the low scenario, as shown in Table 5, which has the dominant effect. In addition, due to the cumulative effect of population age distribution, the three lines are gradually diverging and end up with 80,384, 79,106, and $77,743 \mathrm{GWh}$ in 2031, respectively.

Another important point that should be mentioned is that even the lowest forecasts reflecting demographical effects produce higher values than those that do not include any demographic effects. The black-stared line is constantly below the green-dotted line and results in 74,056 GWh in 2031.

The purpose of economic forecasting on residential electricity consumption in this section is not the evaluation of forecasting accuracy, rather it is an evaluation of the role of population age distribution. Throughout the section, we verify that demographical change plays an important role in electricity consumption forecasting based on the three scenario cases. Furthermore, including 
demographic effects in the regression model produces quite different forecasts than models without demographical effects.

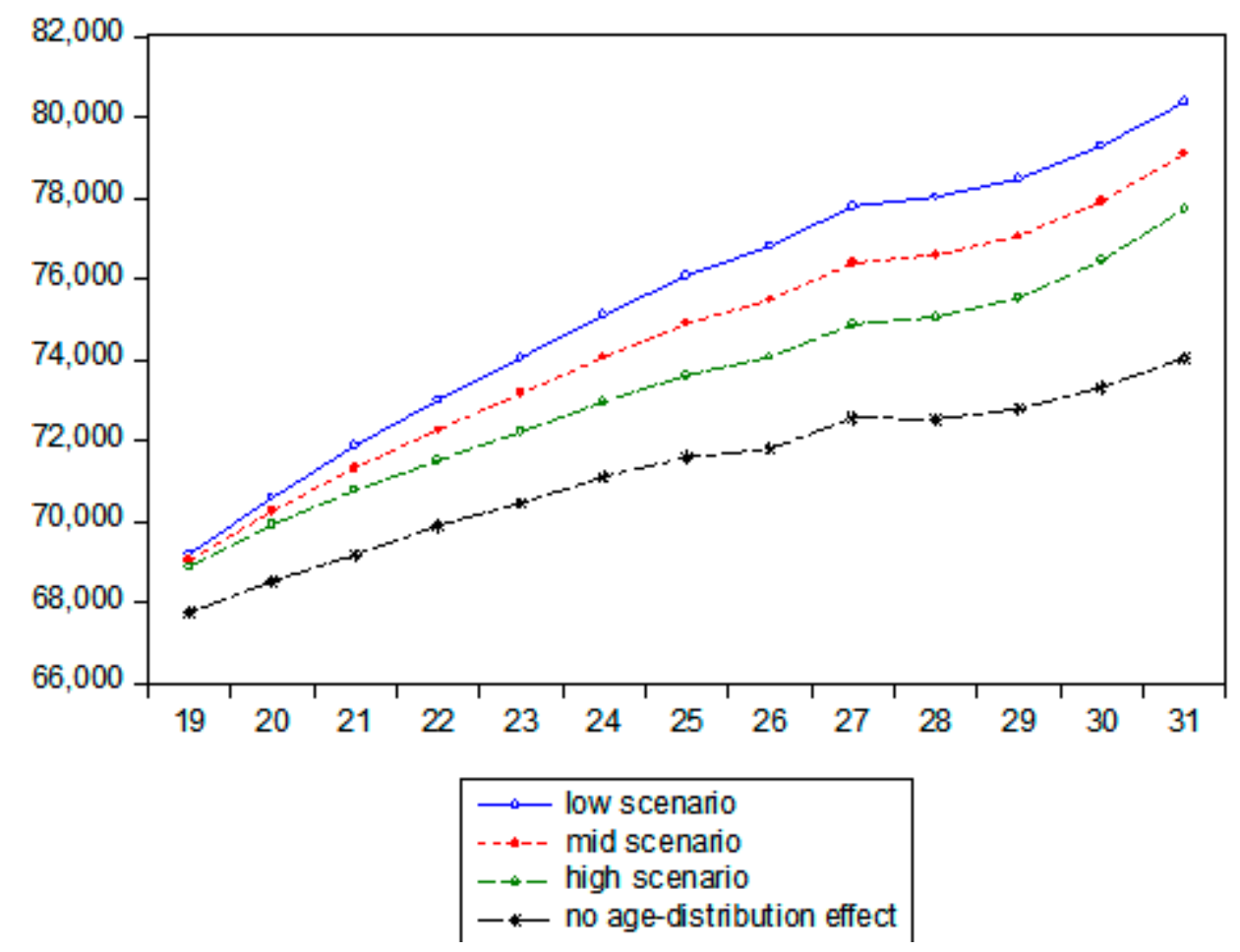

Figure 5. Results of future forecasted residential electricity consumption.

\section{Conclusions and Policy Implications}

In this study, we investigate the impact of population age distribution on residential electricity consumption. Unlike previous literature, we use Korean regional-panel data, not household cross-sectional survey data. Most importantly, we apply population polynomials, allowing us to incorporate all the demographic profile information instead of including single variables, such as the share of the population aged over 65 or the aging index.

The overall estimation results show us that the population age distribution has a statistically significant effect on residential electricity consumption. To be specific, populations aged 20 44, who actively use many electronic gadgets, raise residential electricity consumption. On the other hand, populations aged 45 59 reduce residential electricity consumption, but only by a small amount. Populations aged over 60 raise electricity consumption again since older generations tend to stay home longer, need more heating and cooling to maintain their health, and exhibit diseconomies of scale because older households generally consist of only one or two people. Additionally, we conduct robustness test to verify that our baseline results are solid by conditioning them on different income groups and different time periods. We find that there is a slight difference from the robustness test, but overall, the results are qualitatively the same as the baseline results.

Finally, we perform long-term conditional forecasting for future residential electricity consumption in 2019 2031 using publicly available projected values for the macroeconomic, climate, and demographic variables. We apply three different scenarios, a low, middle, and high scenario, in ascending order of variability in terms of total fertility rate, life expectancy, and net international mobility. In order to evaluate the role of demographic variables more concretely, we produce a long-term forecast of electricity without demographical factors. We conclude that population age distribution, represented by population aging, plays an important role in long-term forecasting, and exerts a more dominant effect than total population growth. 
Considering that low fertility and population aging are accelerated in Korea, we find several policy implications. First, understanding electricity consumption patterns must take precedence in order to implement effective GHG reduction and electricity demand management policies. An increase in income level could contribute to awareness of energy conservation, but the difference in electricity consumption patterns might diminish this effect ([2] identify the determinants of energy conservation behavior. They find that an increase in age and income have positive effects on energy conservation, but the magnitudes are slight. Additionally, ref. [4] show empirical results that suggest energy conservation awareness has no significant effect on residential electricity consumption).

Second, in designing the energy efficiency improvement policies, older populations should be carefully considered. Based on our research, populations aged over 60 consume more electricity than populations aged 45 59 in per capita terms and we interpret this as those populations needing more energy for heating and cooling. Energy consumption for heating and cooling is difficult to reduce, and those expenditures can be a burden on older people since many in Korea suffer from poverty in old age ([47] indicates that old-age poverty in Korea reached $45.7 \%$, which is the highest among the OECD nations). Many energy efficiency improvement policies have been introduced by local governments and national agencies in Korea, but until now policies targeting older populations have been rare. From now on, more sophisticated, nation-wide policies will be needed to address the energy efficiency improvement for older people.

Third, in order to design more a comprehensive energy plan, and to improve the accuracy of energy consumption forecasts, population age distribution should be fully considered. There is significant evidence from previous literature that demographic variables directly affect energy consumption through consumer behavioral patterns. However, those factors are still omitted in the primary statistical model in the Korean 'National Basic Plan on Electricity Demand', and they have only recently, and partially, been considered in the secondary model because those factors are believed to primarily affect national income, such as GDP.

The limitations of this study and suggestions for further improvements are as follows. First, we could not reflect various explanatory variables because we use macroeconomic regional panel data. Microeconomic household survey data would allow us to include various characteristic variables, such as size of household, education level, house tenure, and so on. To the best of our knowledge such household energy panel data for the long period is difficult to find internationally. In Korea we have the Household Energy Standing Survey (HESS), which is a comprehensive survey about various energy consumption and household characteristics provided by the Korean Energy Economics Institute. However, this survey has only existed for a few years, which is too short, and most importantly the survey is repeated cross-sectional data, not panel data. Fortunately, pseudo-panel data methodology, which is transforming the data structure from cross-sectional data based on specific information is now somewhat used, so we can extend our analysis in the future [6]. Second, we only focus on the demand side of energy, as most previous articles do. However, a few of them consider both supply and demand at the same time $[17,22]$. The working age population is an essential input in production, so production may decrease due to population aging. Lowered labor input will have a negative effect on economic production, all other inputs being equal, and this may decrease energy consumption. From this perspective, we need to consider both supply and demand at the same time, and general equilibrium models should be applied since the univariate reduced form econometric model has limitations in analyzing both sides. We leave this to future research.

Author Contributions: Data curation, H.-H.J., J.K.; Formal analysis, M.J.; Methodology, J.K.; Supervision, H.-H.J.; Writing-original draft, M.J. All authors have read and agreed to the published version of the manuscript.

Funding: This research received no external funding.

Acknowledgments: The authors are grateful to reviewers and editors for helpful comments and suggestions.

Conflicts of Interest: This work is partly based on Jang's doctoral thesis. 


\section{References}

1. Glenn, J.C.; Gordon, T.J.; Florescu, E. 2011 State of the Future, The Millennium Project. Available online: http://www.millennium-project.org/publications-2-3/ (accessed on 13 December 2018).

2. Hori, S.; Kondo, K.; Nogata, D.; Ben, H. The determinants of household energy-saving behavior: Survey and comparison in five major Asian cities. Energy Pol. 2013, 52, 354-362. [CrossRef]

3. Shove, E.; Walker, G. What Is Energy For? Social Practice and Energy Demand. Theor. Cult. Soc. 2014, 31, 41-58. [CrossRef]

4. Wallis, H.; Nachreiner, M.; Matthies, E. Adolescents and electricity consumption; Investigating sociodemographic, economic, and behavioural influences on electricity consumption in households. Energy Pol. 2016, 94, 224-234. [CrossRef]

5. Yang, S.; Zhang, Y.; Zhao, D. Who exhibits more energy-saving behavior in direct and indirect ways in china? The role of psychological factors and socio-demographics. Energy Pol. 2016, 93, 196-205. [CrossRef]

6. Bardazzi, R.; Pazienza, M.G. Switch off the light, please! Energy use, aging population and consumption habits. Energy Econ. 2017, 65, 161-171. [CrossRef]

7. Elnakat, A.; Gomez, J.; Booth, N. A zip code study of socioeconomic, demographic, and household gendered influence on the residential energy sector. Energy Rep. 2016, 2, 21-27. [CrossRef]

8. Kim, J.; Jang, M.; Shin, D. Examining the Role of Population Age Structure upon Residential Electricity Demand: A Case from Korea. Sustainability 2019, 11, 3914. [CrossRef]

9. Kim, D.K.; Park, S. The Impact of Population Aging on Energy Use and Carbon Emissions in Korea. J. Environ. Pol. 2014, 13, 99-129. [CrossRef]

10. Noh, S.; Lee, H. An analysis of the factors affecting the energy consumption of the household in Korea. J. Korea Plan. Assoc. 2013, 48, 295-312.

11. O'Neill, C.B.; Chen, B.S. Demographic Determinants of Household Energy Use in the United States. Popul. Dev. Rev. 2002, 28, 53-88.

12. Yamasaki, E.; Tominaga, N. Evolution of an aging society and effect on residential energy demand. Energy Pol. 1997, 25, 903-912. [CrossRef]

13. York, R. Demographic trends and energy consumption in European Union Nations, 1960-2025. Soc. Sci. Res. 2007, 36, 855-872. [CrossRef]

14. Roberts, S. Demographics, energy and our homes. Energy Pol. 2008, 36, 4630-4632. [CrossRef]

15. Zhou, S.; Teng, F. Estimation of urban residential electricity demand in China using household survey data. Energy Pol. 2013, 61, 394-402. [CrossRef]

16. Brounen, D.; Kok, N.; Quigley, J.M. Residential energy use and conservation: Economics and demographics. Eur. Econ. Rev. 2012, 56, 931-945. [CrossRef]

17. Garau, G.; Lecca, P.; Mandras, G. The impact of population ageing on energy use: Evidence from Italy. Econ. Model. 2013, 35, 970-980. [CrossRef]

18. Lim, H.; Jung, S.; Won, D. An analysis of the impact of Global Warming on residential energy consumption: Focused on the case of electricity consumption. Korean Energy Econ. Rev. 2013, 12, 33-58. [CrossRef]

19. No, J. Effects of Demographics and usage of appliances on household electricity demand in Korea. J. Korean Econ. Stud. 2014, 32, 177-202.

20. Ota, T.; Kakinaka, M.; Kotani, K. Demographic effects on residential electricity and city gas consumption in the aging society of Japan. Energy Pol. 2018, 115, 503-513. [CrossRef]

21. Kim, J.; Lim, H.; Jo, H.-H. Do Aging and Low Fertility Reduce Carbon Emissions in Korea? Evidence from IPAT Augmented EKC Analysis. Int. J. Environ. Res. Public Health 2020, 17, 2972. [CrossRef]

22. Dalton, M.; O’Neill, B.; Prskawetz, A.; Jiang, L.; Pitkin, J. Population aging and future carbon emissions in the United States. Energy Econ. 2008, 30, 642-675. [CrossRef]

23. Hamza, N.; Gilroy, R. The challenge to UK energy policy: An ageing population perspective on energy saving measures and consumption. Energy Pol. 2011, 39, 782-789. [CrossRef]

24. Arisoy, I.; Ozturk, I. Estimating industrial and residential electricity demand in Turkey: A time varying parameter approach. Energy 2014, 66, 959-964. [CrossRef]

25. Chang, Y.; Kim, C.S.; Miller, J.I.; Park, J.Y.; Park, S. Time-varying Long-run Income and Output Elasticities of Electricity Demand with an Application to Korea. Energy Econ. 2014, 46, 334-347. [CrossRef] 
26. Chang, Y.; Kim, C.S.; Miller, J.I.; Park, J.Y.; Park, S. A new approach to modeling the effects of temperature fluctuations on monthly electricity demand. Energy Econ. 2016, 60, 206-216. [CrossRef]

27. Chang, Y.; Choi, Y.; Kim, C.S.; Miller, J.I.; Park, J.Y. Disentangling temporal patterns in elasticities: A functional coefficient panel analysis of electricity demand. Energy Econ. 2016, 60, 232-243. [CrossRef]

28. Mirasgedis, S.; Sarafidis, Y.; Georgopoulou, E.; Lalas, D.; Moschovits, M.; Karagiannis, F.; Papakonstantinou, D. Models for mid-term electricity demand forecasting incorporating weather influences. Energy 2006, 31, 208-227. [CrossRef]

29. Mohamed, Z.; Bodger, P. Forecasting electricity consumption in New Zealand using economic and demographic variables. Energy 2005, 30, 1833-1843. [CrossRef]

30. Kim, J.; Seo, B. Aging in population and energy demand. In Proceedings of the 3rd IAEE Asian Conference, Kyoto, Japan, 20-22 February 2012; pp. 66-78.

31. Liddle, B.; Lung, S. Age-structure, urbanization, and climate change in developed countries: Revisiting STIRPAT for disaggregated population and consumption-related environmental impacts. Popul. Environ. 2010, 31, 317-343. [CrossRef]

32. Liddle, B. Consumption-Driven Environmental Impact and Age Structure Change in OECD Countries. Demogr. Res. 2011, 24, 749-770. [CrossRef]

33. Fu, C.; Wang, W.; Tang, J. Exploring the sensitivity of residential energy consumption in China: Implications from a micro-demographic analysis. Energy Res. Soc. Sci. 2014, 2, 1-11. [CrossRef]

34. Shin, D.; Jo, H.; Jang, M. An Analysis on the Heterogeneity of Residential Electricity Consumption Depending on Income Level: Evidence from Urban Household in South Korea. Korean Energy Econ. Rev. 2015, 14, $27-81$. [CrossRef]

35. Fair, R.; Dominguez, K. Effects of the Changing U.S. Age Distribution on Macroeconomic Equations. Effects Chang. U.S. Age Distrib. Macroecon. Equ. 1987, 81, 1276-1294. [CrossRef]

36. Pachauri, S. An analysis of cross-sectional variations in total household energy requirements in India using micro survey data. Energy Pol. 2004, 32, 1723-1735. [CrossRef]

37. Kronenberg, T. The impact of demographic change on energy use and greenhouse gas emissions in Germany. Ecol. Econ. 2009, 68, 2637-2645. [CrossRef]

38. Higgins, M. Demography, National Savings, and International Capital Flows. Int. Econ. Rev. 1998, $39,343$. [CrossRef]

39. Arnott, R.D.; Chaves, D.B. Demographic Changes, Financial Markets, and the Economy. Financ. Anal. J. 2012, 68, 23-46. [CrossRef]

40. Juselius, M.; Takáts, E. Can demography affect inflation and monetary policy? BIS Working Papers No. 485. 2015. Available online: https://ssrn.com/abstract=2562443 (accessed on 27 November 2017).

41. Sanquist, T.F.; Orr, H.; Shui, B.; Bittner, A.C. Lifestyle factors in U.S. residential electricity consumption. Energy Pol. 2012, 42, 354-364. [CrossRef]

42. Schröder, C.; Rehdanz, K.; Narita, D.; Okubo, T. Household Formation and Residential Energy Demand: Evidence from Japan. Kiel Working Paper 1836. 2013. Available online: https://www.econstor.eu/handle/ 10419/73677 (accessed on 9 July 2019).

43. The Stationery Office Limited. Ageing: Scientific Aspects; House of Lords: London, UK, 2005.

44. Munnell, H.A.; Sundén, A. Death and Dollars: The Role of Gifts and Bequest in America; The Brookings Institution: Washington, DC, USA, 2003.

45. Menz, T.; Kühling, J. Population aging and environmental quality in OECD countries: Evidence from sulfur dioxide emissions data. Popul. Environ. 2011, 33, 55-79. [CrossRef]

46. Ministry of Trade, Industry and Energy. The 8th Basic Plan for Long-term Electricity Supply and Demand (2017-2031); Ministry of Trade, Industry and Energy: Sejong-city, Korea, 2017.

47. OECD. Pensions at a Glance 2017: OECD and G20 Indicators; OECD Publishing: Paris, France, 2017.

Publisher's Note: MDPI stays neutral with regard to jurisdictional claims in published maps and institutional affiliations. 